\title{
ANALISIS IDEOLOGI PADA NOVEL “AYAT-AYAT CINTA 2": ANALISIS WACANA KRITIS MODEL VAN DIJK
}

\section{THE IDEOLOGY ANALYSIS ON "AYAT-AYAT CINTA 2'S" NOVEL : CRITICAL DISCOURSE ANAL YSIS MODEL VAN DIJK}

\author{
Wahyu Ningsih ${ }^{1}$, T. Silvana Sinar ${ }^{2}$. T. Thyrhaya Zein ${ }^{3}$. \\ ${ }^{1}$ (Linguistik, Universitas Sumatera Utara, Indonesia) \\ ${ }^{2}$ (Linguistik, Universitas Sumatera Utara, Indonesia) \\ ${ }^{3}$ (Linguistik, Universitas Sumatera Utara, Indonesia) \\ Hp. 082160779587 \\ email.wahyu27071987@gmail.com
}

Naskah diterima tanggal 19 Oktober 2018

Naskah direvisi terakhir tanggal 26 September 2019

\begin{abstract}
Ideology in a novel is a central concept in Critical Discourse Analysis. One of the novel authors who has a view of the surrounding existence through an ideology is Habiburahman El Shirazy. This studied aimed to find out how the ideology that underlies Ayat-ayat cinta's novel 2 by Habiburahman El Shirazy and what context triggers the ideology. To answer the research question, this research used van Dijk's Critical Discourse Analysis theory. This type of research was included in the type of content analysis research. The data in this study was sentences and paragraphs. Based on the results of the study, it was known that the ideology underlying the novel Ayat-ayat cinta's novel 2 by Habiburahman El Shirazy was an Islamic ideology and the context that triggers the ideology was how Habiburrahman El Shirazy views the western perception of Islam, views on dating in Islam, and based on the biography of Habiburrahman El Shirazy. Overall the Ayat-Ayat Cinta 2's novel was a novel that reminds the reader of being able to at least change the mindset by reading and understanding the Qur'an well.
\end{abstract}

Keywords: Ayat-ayat cinta 2, Ideology, Critical Discourse Analysis

\begin{abstract}
Abstrak
Ideologi pada sebuah novel merupakan konsep sentral dalam Analisis Wacana Kritis. Salah satu pengarang novel yang memiliki pandangan tentang keberadaan sekitarnya melalui sebuah ideologi adalah Habiburahman El Shirazy. Penelitian ini bertujuan untuk mengetahui bagaimana bentuk ideologi yang mendasari novel Ayat-ayat cinta 2 karya Habiburahman El Shirazy dan konteks apa yang memicu ideologi tersebut. Untuk menjawab pertanyaan penelitian tersebut, maka penelitian ini menggunakan teori Analisis Wacana Kritis van Dijk. Jenis penelitian ini termasuk ke dalam jenis penelitian analisis isi. Data pada penelitian ini adalah kalimat dan paragraf. Berdasarkan hasil penelitian diketahui ideologi yang mendasari novel Ayat-ayat cinta 2 karya Habiburahman El Shirazy adalah ideologi Islam dan adapun konteks yang memicu ideologi tersebut yaitu bagaimana pandangan Habiburrahman El Shirazy terhadap persepsi barat terhadap Islam, pandangan tentang cara berpacaran dalam Islam, dan berdasaran biografi Habiburrahman El Shirazy. Secara menyeluruh novel AyatAyat Cinta 2 adalah novel yang mengingatkan pembaca setidaknya mampu merubah pola pikir dengan membaca dan memahami Al-Qur'an dengan baik.
\end{abstract}

Kata Kunci : Ayat-ayat cinta 2, Ideologi, Analisis Wacana Kritis

\section{PENDAHULUAN}

Novel merupakan satu bentuk cerita rekaan yang kompleks dan bermakna. Novel sebagai salah satu jenis karya sastra mampu menghancurkan tatanan kekuasaan, hingga sikap-sikap intimidasi individu. (Sugihastuti 
dan Suharto, 2002). Salah satu novel yang mengandung tentang keteladanan tokoh dan hal-hal positif serta mengajarkan tentang kebaikan adalah novel Ayat-Ayat Cinta 2 karya Habiburrahman El Shirazy yaitu seorang novelis nomor 1 di Indonesia. Selain novelis, Habiburrahman El Shirazy juga dikenal sebagai sutradara, dai, penyair, sastrawan, pimpinan pesantren, dan penceramah.

Secara umum tokoh-tokoh yang berperan dalam novel Ayat-Ayat Cinta 2 karya Habiburrahman El Shirazy terdiri atas tokoh laki-laki dan perempuan yang selalu ditampilkan dengan berbagai permasalahan, peran, fungsi, serta citranya mengarahkan pembaca pada pengimajinasian yang dibuat oleh pengarang yang dapat diungkapkan melalui citra yang menyerupai gambaran yang dihasilkan oleh hasil tafsiran pembaca terhadap suatu objek.

Pemilihan novel Ayat-Ayat Cinta 2 karya Habiburrahman El Shirazy sebagai subjek penelitian dilatarbelakangi oleh adanya keinginan peneliti untuk menemukan ideologi yang terkandung pada novel tersebut dan apa yang melatarbelakangi Habiburrahman El Shirazy memilih ideologi tersebut.

Hadirnya ideologi pada sebuah novel bertujuan untuk menawarkan perubahan, memperbaiki tatanan yang sudah ada, atau bahkan mengubah total kebiasaan (Roekminto, 2008). Ideologi memiliki dua pengertian yang bertolak belakang, yakni secara positif dan secara negatif. Secara positif, ideologi dipersepsi sebagai suatu pandangan yang menyatakan nilai kelompok sosial tertentu untuk membela dan memajukan kepentingan-kepentingannya. Sedangkan secara negatif, ideologi dilihat sebagai suatu kesadaran palsu, yaitu suatu kebutuhan untuk melakukan penipuan dengan cara memutarbalikkan pemahaman orang mengenai realitas social (hlm. 2).

Menurut van Dijk (1993), ideologi dimaksudkan untuk mengatur masalah tindakan dan praktik individu atau anggota suatu kelompok yang bersifat umum dan abstrak, serta menjadikan nilai-nilai yang ada menjadi dasar bagaimana wacana bukan hanya sebagai barang yang alamiah, akan tetapi juga sebagai seperangkat gagasan atau kepercayaan yang dimiliki oleh golongan tertentu yang mempunyai tujuan sehingga menuntut orang yang meyakininya melakukan tindakan-tindakan tertentu.

Penelitian tentang ideologi pada novel Ayat-Ayat Cinta 2 karya Habiburrahman El Shirazy ini menitikberatkan pada teori Analisis Wacana Kritis model van Dijk (1993). Adapun alasan peneliti menitikberatkan penelitian ini pada model van Dijk (1993) karena model ini melihat suatu teks terdiri atas beberapa struktur atau tingkatan yang saling mendukung, salah satunya adalah struktur mikro yang terdapat dalam novel tersebut. Stuktur mikro yang dimaksud pada penelitian ini ialah diksi yang dipakai oleh pengarang pada sebuah novel.

Struktur mikro dapat membongkar sebuah ideologi yang terkandung pada sebuah novel.

Analisis Wacana Kritis model van Dijk (1993) berbeda dengan Analisis Wacana Kritis tokoh lain. Tokoh-tokoh Analisis Wacana Kritis tersebut lebih cenderung memusatkan perhatian pada pertarungan politik, kekuasaan, dan gender. Seperti Foucault (1971) yang menganggap bahwa wacana merupakan alat bagi kepentingan kekuasaan, hegemoni, dominasi budaya, dan ilmu pengetahuan. Leeuwen (2001) menganalisis bagaimana suatu kelompok atau seseorang dimarginalisasi posisinya dalam suatu wacana. Mills (1994) yang memusatkan perhatian pada bagaimana pembaca memengaruhi bagaimana seharusnya teks itu dipahami dan bagaimana aktor sosial ditempatkan. Penceritaan dan posisi yang menjadikan satu pihak legitimate dan pihak lain illegitimate. Sedangkan van Dijk (1993) secara detail menganalisis wacana berdasarkan struktur makro, superstruktur dan mikrostruktur (hlm. 68).

Berdasarkan paparan di atas, peneliti tertarik untuk menganalisis novel Ayat-Ayat Cinta 2 karya Habiburrahman El Shirazy dengan Analisis Wacana Kritis model van 
Dijk (1993). Adapun tujuan penelitian ini yaitu untuk mengetahui ideologi apa yang terkandung pada novel Ayat-Ayat Cinta 2 karya Habiburrahman El Shirazy dan konteks apa yang memicu ideologi tersebut. Adapun data pada penelitian ini adalah kalimat dan paragraf yang mengandung ideologi pada novel Ayat-Ayat Cinta 2 karya Habiburrahman El Shirazy.

\section{PEMBAHASAN}

Adapun bentuk-bentuk ideologi yang terdapat pada novel Ayat-Ayat Cinta 2 Karya Habiburrahman El Shirazy dapat dilihat sebagai berikut:

2.1 Ideologi pada Novel Ayat-Ayat Cinta 2 Karya Habiburrahman El Shirazy

Adapun hasil analisis bentuk ideologi pada novel Ayat-Ayat Cinta 2, yaitu sebagai berikut :

Data 1 AAC2/2 Suara khas bigpipe menggema dari Plaza

Saint Giles Cathedral yang berdiri anggun menawan. Seorang

lelaki tua berkumis pirang berpakaian tradisional Skotlandia tampak begitu

khusyuk meniup alat musik bangsa Scots yang legendaris itu. Pakaian yang ia kenakan sangat khas memakai awahan seperti rok yang disebut kilt berornamen tartan kotak-kotak merah hitam. Atasan jas hitam khas Skotlandia. Juga dengan topi yang khas. Terkadang ia tampak begitu bersemangat, seperti sedang menggerakkan ribuan tentara di medan perang dengan terompet bigpipe itu.
(Ayat-Ayat Cinta 2, Hlm. 2)

Pada data 1 AAC2/2 di atas terdapat kalimat yang mendeskripsikan kehidupan yang teratur, rapi dan terstruktur. Habiburrahman El Shirazy memilih kalimatkalimat yang menunjukkan adanya keteraturan masyarakat pada sebuah negara dimana tokoh utama pada novel ini tinggal. Keteraturan tersebut terlihat pada kalimat yang menceritakan aktivitas seorang lelaki tua berkumis pirang berpakaian tradisional Skotlandia yang tampak begitu khusyuk meniup alat musik bangsa Scots yang legendaris. Pakaian yang ia kenakan sangat khas memakai bawahan seperti rok yang disebut kilt berornamen tartan kotakkotak merah hitam, atasan jas hitam khas Skotlandia. Juga dengan topi yang khas. Hal tersebut menunjukkan bahwa Habiburrahman El Shirazy adalah seorang pribadi yang konservatif atau menyukai kegiatan tradisi dari zaman dahulu yang masih di jaga kelestariannya. Sehingga dapat disimpulkan bahwa Habiburrahman El Shirazy menggunakan ideologi konservatisme yaitu suatu ideologi yang menganut paham bahwa masyarakat harus tertata baik, damai, dan mencintai tradisi yang telah ada turun-temurun seperti yang terdapat pada paragraf di atas.

\section{Data 2 AAC2/3 La haula wa Ia quwwata illa billah, La haula wa la quwwata illa billah ... Lelaki itu bergumam mengulang-ulang zikirnya (Ayat-Ayat Cinta 2, Hlm. 3)}

Pada data 2 AAC2/3 di atas terdapat kalimat yang merupakan salah satu ayat kutipan yaitu "La haula wa Ia quwwata illa billah, La haula wa la quwwata illa billah" yang artinya tidak ada situasi dan kekuatan untuk Tuhan, tidak ada negara dan tidak ada kekuatan kepada Tuhan. Melalui kalimat tersebut Habiburrahman El Shirazy 
mendeskripsikan dirinya melalui sosok Fahri sebagai sosok yang agamais. Pada data tersebut di atas, terdapat ideologi Islam yang ditandai dengan adanya kalimat yang mengharuskan manusia harus mengingat Allah agar dalam kondisi apa pun, kapan pun dan di mana pun hendaklah manusia mengingat Allah dan selalulah berzikir kepada Allah.

Data 3 AAC2/5 Satu hal yang harus kalian catat, hal pertama yang harus dimiliki seorang philologist adalah amanah. Saya diminta oleh Professor Charlotte untuk mengeluarkan dari kelas ini siapa saja yang belum membaca dua buku itu. Tanpa pandang bulu. Maka saya harus amanah. Tadi Juu Suh sudah saya keluarkan dari kelas. Dan selanjutnya, adalah kewenangan saya untuk memberinya kesempatan masuk kembali ke dalam kelas. Amanah Professor Charlotte sudah saya laksanakan. (AyatAyat Cinta 2, Hlm. 5)

Pada data 3 AAC2/5 di atas di ceritakan kegiatan yang berlangsung dalam ruangan kelas. Kalimat "maka saya harus amanah" menunjukkan sosok seorang muslim yang taat. Ideologi yang tercermin pada paragraf tersebut adalah ideologi Islam yaitu seorang muslim sejati adalah muslim yang amanah dan tidak takut melakukan kebenaran.
Data 4 AAC2/5

Maaf, bagi saya ini sudah tiba waktunya untuk ibadah. Apakah kalian terganggu jika saya shalat di sini? Jika kalian terganggu, saya akan shalat di office saya, lalu balik ke sini (Ayat-Ayat Cinta 2, Hlm. 5)

Pada data 4 AAC2/5 di atas terjadi interaksi antara mahasiswa dan dosen dalam sebuah ruangan kelas. Habiburrahman El Shirazy menggambarkan karakter dirinya yang demokrat melalui tokoh Fahri yang selalu menghargai keyakinan agama lain, dengan mempertanyakan terlebih dahulu apakah para mahasiswa terganggu apabila Fahri melakukan ibadah di dalam ruangan kelas. Melalui kalimat "bagi saya ini sudah tiba waktunya untuk ibadah" menunjukkan bahwa ideologi pada penggalan novel ini adalag ideologi Islam.

\begin{tabular}{|c|c|}
\hline Data 5 AAC2/6 & $\begin{array}{lr}\text { Fahri } & \text { kemudian } \\
\text { shalat } & \text { dipojok } \\
\text { ruangan } & \text { itu } \\
\text { menghadap } & \text { kiblat. } \\
\text { Sebagian mahasiswa } \\
\text { terutama dua orang } \\
\text { mahasiswa bule dan } \\
\text { mahasiswi bermata } \\
\text { sipit } \\
\text { memerhatikan } \\
\text { gerakan itu } \\
\text { dengan } \\
\text { Selesai shalat } \\
\text { Ayat Cinta } 2, \text { Hlm. }\end{array}$ \\
\hline
\end{tabular}

Pada data 5 AAC2/6 di atas terdapat sebuah ideologi, yaitu ideologi Islam yang ditunjukkan melalui kalimat "Fahri kemudian shalat dipojok ruangan itu menghadap kiblat". Bagi Fahri, ibadah adalah segala-galanya yang tidak dapat ditukar dengan apa pun di dunia ini. Tindakan tokoh utama yang tidak mau meninggalkan jadwal ibadahnya meskipun pada saat melaksanakan tugas mengajar. 
Data 6 AAC2/6-7 Satu pertanyaan saya, kenapa orang Muslim suka bom bunuh diri? Fahri agak kaget mendengar

pertanyaan itu. Dan ia merasa tidak boleh bosan atau lelah untuk menjawab segala pertanyaan demi menyampaikan informasi yang jujur. Selama itu tidak sekalipun saya mendapatkan adanya ajaran bom bunuh diri. Tidak ada satu pun yang busuk? Tidak ada yang jatuh dari pohonnya sebelum matang? Mahasiswi dari Cina spontan menjawab, —Tidak bisa. Selalu ada satu dua dari pohon itu yang buahnya tumbuh tidak yang diharapkan. Satu ada yang busuk. Tidak bisa semua buahnya sempurna (Ayat-Ayat Cinta 2, Hlm. 6-7)

Pada data 6 AAC2/6 di atas terdapat sebuah kalimat imperatif yang meminta jawaban yang jujur berdasarkan fakta, yaitu tentang pandangan buruk umat manusia terhadap pelaku bom bunuh diri yang dilakukan oleh umat Islam. Oleh sebab itu Fahri yang merupakan seorang tokoh intelektual dan cerdas yang mampu menjawab pertanyaan-pertanyaan yang mematikan mengenai perbedaan agama dengan santai dan bahkan mampu memberikan analogi sederhana namun tepat sasaran. Pada paragraf ini tokoh Fahri dideskripsikan sebagai tokoh yang sabar dan tidak mudah marah dalam memberikan jawaban. Dan jawaban-jawaban yang diberikan atas pertanyaan yang seharusnya menyinggung perasaannya ia jawab dengan santai. Sehingga dapat disimpulkan bahwa ideologi yang terdapat pada data di atas adalah ideologi Islam.

$\begin{array}{llr}\text { Data } 7 \text { AAC2/8 Ia melakukan } & \text { kajian } \\ & \text { tahqiq dan ta'liq } \\ & \text { secara ilmiah atas } \\ & \text { kumpulan } & \text { wasiat } \\ & \text { Al_Allamah Habib }\end{array}$ Hasan bin Shaleh AlBahr berjudul Majmu' Washaya yang manuskripnya ia temukan di perpustakaan pribadi Habib Assegaf Solo, Indonesia.

Menghadaplah kepada Allah dengan hati luluh. Hindarkan dirimu dari sikap ujub dan angkuh. Pergaulilah manusia yang jahat dengan baik, karena pada hakikatnya kamu sedang bermuamalah dengan Allah yang Maha besar. Ulurkan tanganmu kepada orang-orang fakir dengan sesuatu yang dikaruniakan Allah kepadamu (Ayat-Ayat Cinta 2, Hlm. 8)

Pada data 7 AAC2/8 di atas terlihat keintiman Habiburrahman El Shirazy melalui tokoh Fahri dengan Allahnya. Sebagai seorang dosen yang mengajar mata kuliah Filologi, Fahri harus mampu memahami dengan baik bagaimana kaitan pelajaran yang satu dengan yang lain. Dengan bacaan tersebut Fahri membenahi dirinya agar selalu menyerahkan segenap hidupnya kepada Allah. Kemudian setelah diketahui bagaimana sejarah manuskrip itu tiba di solo Fahri langsung memberikan rasa 
syukur kepada Allah yang sangat ia cintai dan selalu menjadi pribadi pertama yang mengetahui kebahagiaan Fahri. Jika ada hadis ia mencoba meneliti ulang takhrij hadisnya. Jika ada kalimat yang muskil, ia mencoba mengurai kemuskilan itu dari beberapa sudut pandang dengan rujukan yang ilmiah sesuai disiplin ilmu filologi yang ia kuasai. Berdasarkan paragraf di atas diketahui bahwa Habiburrahman El Shirazy menyelipkan ideologi Islam, yang pada paragraf tersebut terdapat sosok manusia yang sangat mencintai Allahnya dan memiliki kecerdasan yang matang.

1.2. Konteks yang memicu Ideologi yang Mendasari Novel Ayat-Ayat Cinta 2 Karya Habiburrahman El Shirazy

Ada beberapa konteks yang memicu ideologi yang mendasari novel Ayat-Ayat Cinta 2 karya Habiburrahman El Shirazy, yaitu:

\subsubsection{Pandangan Habiburrahman EI Shirazy terhadap persepsi barat terhadap Islam}

Berdasarkan

pandangan

Habiburrahman El Shirazy terhadap cara pandang barat terhadap Islam, orang barat memberikan reaksi spontan terhadap keadaaan umat Islam di negara-negara Islam tanpa memperhatikan apa sesungguhnya ajaran Islam itu sendiri secara menyeluruh melainkan sepenggal-sepenggal sesuai dengan kebutuhan mereka dalam memaknai Islam. Oleh sebab itu Habiburrahman El Shirazy tidak heran dengan adanya pandangan negatif barat kepada Islam, namun juga tidak dapat disembunyikan bahwa pandangan Barat tersebut seringkali disebabkan oleh salah paham, atau malah oleh rasa permusuhan. Apalagi dengan adanya benturan budaya modern Barat, maka rasa permusuhan yang laten kepada Islam itu semakin memperoleh bahan pembenaran.

Pandangan negatif barat kepada Islam tersebut Habiburrahman El Shirazy deskripsikan melalui kehidupan Fahri pada novel Ayat-Ayat Cinta 2. Seperti yang terdapat pada penggalan novel berikut ketika salah seorang mahasiswanya bertanya kepadanya mengenai orang-orang Muslim yang sering melakukan bom bunuh diri, yaitu: "Satu pertanyaan saya, kenapa orang Muslim suka bom bunuh diri? Fahri agak kaget mendengar pertanyaan itu. Dan ia merasa tidak boleh bosan atau lelah untuk menjawab segala pertanyaan demi menyampaikan informasi yang jujur" Untuk merespon pertanyaan tersebut Fahri menjawab dengan santai seraya berkata bahwa ia tidak pernah mendapatkan adanya ajaran bom bunuh diri. Ketika Fahri mengambil master di Pakistan, juga tidak menemukan ajaran itu Fahri menyelesaikan Ph.D di Freiburg, Fahri mengkaji manuskrip Arab Islam abad pertengahan Sebuah manuskrip Tafsir Al-Qur'an karya Quthbuddin Asy Syirazy yang bernama Fath at-Mannan. Dalam mengkaji manuskrip itu, Fahri harus menyelesaikan dan membaca tak kurang dari sepuluh kitab tafsir dari awal sampai akhir (AyatAyat Cinta 2, Hlm. 6-7).

Penggalan novel tersebut menjelaskan bahwa menurut Habiburrahman El Shirazy begitu buruknya Islam di mata penganut agama lain, sehingga banyak orang berpikir bahwa Islam adalah agama peneror yang tidak segan-segan melakukan aksinya dalam menyakiti dan membunuh orang banyak, sehingga HES berpikir bahwa dibutuhkan sosok-sosok agamawan yang memiliki pemahaman yang kuat untuk merespon seseorang dengan pertanyaan yang sama.

Selain itu, pandangan yang sama dimiliki oleh tetangga Fahri yang merupakan warga negara setempat menyebutnya dengan sebutan Islam Satanic yang terlihat pada coretan di kaca depan mobil SUV. Dalam satu bulan itu adalah kali ketiga kaca depan Fahri dicoret-coret dengan kata yang merendahkah Islam dan Muslim. Selama ini Fahri bersabar saja, ia tidak mengadukan peristiwa itu kepada organisasi-organisasi yang menangani kasus-kasus terkait Islamofobia atau antiMuslim seperti The Islamic Human Rights Commission atau Tell Mama yang 
dijalankan oleh Faith Matters (Ayat-Ayat Cinta 2, Hlm. 22).

Habiburrahman El Shirazy tentunya telah pernah mengalami atau mendengarkan selentingan cerita sesama muslim bagaimana perlakuan para remaja terhadap Muslim di Eropa. Adanya ketidaksukaan terhadap agama Islam membuat orang-orang pembencinya berani melakukan tindakan anarkistis yang merugikan umat Islam, sebagai salah satu contoh adalah perlakukan tetangganya yang sering sekali mencoret-coret kaca mobilnya dengan menuliskan kata-kata yang sangat tidak sopan.

Pandangan buruk terhadap Islam juga tidak hanya datang dari agama di luar Islam, namun di negara barat sesama Islam juga saling memusuhi dan menganggap bahwa Islam yang berasal dari luar negaranya adalah Islam yang tidak taat sehingga muncul diskriminasi terhadap orang Islam yang tidak berasal dari negara yang sama, seperti yang ada pada data berikut:

"Fahri sangat memaklumi dirinya agak diremehkan. Sebab ia berwajah Asia Tenggara dan tidak berjenggot. Imam itu dari Arab, terkadang ada kesombongan dari kalangan Arab bahwa karena dari Arab dan sejak lahir berbahasa Arab, AlQur'an juga diturunkan di Arab dan dalam bahasa Arab, mereka merasa lebih mengerti Islam dan meremehkan yang lain. Orang-orang Asia Selatan sebagian juga ada yang rnerasa lebih memahami Islam dibanding bangsa lain, termasuk Arab. Orang-orang Asia Selatan sering sinis memandang orang-orang Arab terutarma orang-orang Teluk sebagai kakitangan Amerika dan Eropa. Maka wajah seperti Fahri sama sekali tidak masuk perhitungan mereka. Fahri sudah terbiasa diremehkan seperti itu. Dulu saat masih di Mesir, ketika ia membela Aisha yang memberi tempat duduk didalam Metro kepada turis Amerika, ia awalnya juga diremehkan oleh orang Mesir.”
Habiburrahman El Shirazy menilai bahwa perkembangan Islam di dunia barat dijadikan menjadi aksesoris yang kadang hanya untuk menarik perhatian. Ayat Alquran ditulis dalam kaligrafi dengan tinta emas, dibeli dengan harga mahal, tetapi yang punya rumah tidak tahu maknanya, apalagi mengamalkannya. Alquran dijadikan aksesoris sebagai bagian seremonial pembukaan sebuah sekolah, tetapi sekolah itu nantinya mengajarkan hal-hal yang bertentangan dengan Alquran atau peresmian sebuah gedung pertemuan, tetapi gedung itu juga dijadikan tempat menggelar musik-musik maksiat.

Menurut Habiburrahman El Shirazy banyak orang yang merasa dirinya sebagai pembela-pembela Islam yang tangguh. Kerapkali orang-orang yang jujur dan sadar juga sangat gemas dengan pandangan penuh nafsu namun salah dan Zalim dari kalangan orang Barat tentang Islam dan kaum Muslim. Jarang didapat petunjuk dari media, apalagi dari kaum politisi, bahwa kenyataan tentang budaya Islam (baik dahulu maupun kini) bukanlah tidak lain dari sejarah kefanatikan. Sebaliknya, orang pintar bergantian maju untuk meyakinkan umum bahwa orang Arab pada dasarnya adalah sekumpulan kaum maniak agama yang berubah-ubah, pengambil sandera, penghuni semak berduri dan padang pasir yang sepanjang zaman menghalangi mereka untuk kenal dengan negeri-negeri yang lebih beradab.

Seolah-olah orang Amerika selalu dicekoki dengan versi pandangan Islam yang dianut Ferdinand dan Isabella pada abad 15, yang dibesar-besarkan dan disesuaikan dengan zaman. Inti pesannya ialah bahwa orang Arab adalah tidak hanya tidak berbudaya, tetapi tidak dapat dibuat berbudaya.

Pandangan umum yang tidak senang dengan Islam itu, seperti dikatakan dalam kutipan di atas, sudah diidap orang Barat sejak berabad-abad yang lalu, kemudian seolah-olah diperkuat oleh kejadian-kejadian mutakhir yang menyangkut Islam dan umat Islam. 
Interaksi pertama kali antara Islam dan Barat terjadi ketika umat Islam berhasil menguasai Andalusia (Spanyol) sekitar tahun 711 M. Saat itu peradaban Islam sedang berada di puncak kejayaannya, sehingga tidak heran kalau orang-orang Barat banyak belajar kepada umat Islam. Karena saat itu orang Barat merasa dikuasai oleh umat Islam, maka dalam pandangan Barat, Islam adalah penjajah dan mereka harus berjuang untuk melepaskan diri dari penjajahan tersebut. Sehingga ketika Barat kembali berhasil mengalahkan umat Islam di Andalusia mereka memperlakukan orang Islam layaknya musuh yang harus dimusnahkan.

Selanjutnya interaksi Islam dan Barat berlanjut saat terjadinya perang Salib, sebuah peperangan besar antara pasukan kaum muslimin dan laskar kristen selama 300 tahun untuk memperebutkan Yerussalem. Saat itu tentu saja hubungan Islam dan Barat masih berupa permusuhan. Di tengah berkecamuknya Perang Salib, sekitar tahun 1141-1142 ada sekelompok intelektual Barat (Kristen) yang berusaha mempelajari Islam dengan serius. Mereka dipimpin oleh Petrus Venerabilis. Hal pertama yang mereka lakukan adalah menerjemahkan Alquran ke dalam bahasa Latin. Sekalipun terjemahan Alquran tersebut mengandung banyak kekeliruan, namun terjemahan itu tetap menjadi rujukan Barat dalam memandang Islam selama kurang lebih 600 tahun kemudian. Pada fase ini, intinya Barat memandang "Islam sebagai Kristen yang sesat". Maka tak heran jika orang barat banyak menuduh Islam dengan kata-kata kasar dan vulgar. Misalnya mereka mengatakan bahwa Alquran adalah kitab setan, Nabi Muhammad adalah pesuruh setan dan Islam adalah sekte terkutuk, terlaknat sekaligus berbahaya.

Pandangan Barat mengenai Islam seperti itu terus berlangsung hingga abad 16 sehingga muncullah stigma Islam itu simbol teror, perusak, dan barbarian. Bagi orang Eropa, Islam adalah trauma yang tak pernah berakhir. Bahkan tidak sedikit yang menulis bahwa Muhammad adalah penyebar wahyu palsu, tokoh penipu, tidak jujur, pelaku sodomi, yang semuanya itu diambil dari doktrin keagamaan yang dibawanya.

Memasuki abad 17-18, Barat masih tetap memandang Islam dengan pandangan negatif dan penuh api perseteruan. Abad ke 19 Barat menguasai mayoritas wilayah Islam. Mereka banyak mendirikan lembagalembaga studi keislaman dan ketimuran untuk mempelajari Islam secara lebih serius. Hasilnya cara pandang Barat terhadap Islam mengalami pergeseran yang cukup besar, dari fase kebencian dan caci maki menjadi serangan sistimatis dan ilmiah.

Setelah perang dunia II, pandangan Barat mengenai Islam kembali mengalami pergeseran dari sentimen keagamaan yang vulgar menjadi lebih lembut. Banyak mengkritisi ajaran-ajaran Islam, seperti mengkritisi konsep wahyu dan cara menafsirkannya. Walaupun demikian pandangan Barat tetap saja rasial, imperialis, dan etnocentris, mereka sering menuduh Islam dan umatnya dengan tuduhan negatif, seperti teroris.

\subsubsection{Pandangan Habiburrahman El Shirazy tentang Cara Berpacaran dalam Islam}

Novel Ayat-Ayat Cinta 2 karya Habiburrahman El Shirazy adalah novel yang memiliki nilai dakwah yang tertuang dan tidak terkesan menggurui sebagaimana yang ditemukan dalam guratan novel lain. Pesan yang disampaikan melalui Fahri sebagai tokoh utamanya, menjadi teladan bagi generasi muda sekarang dalam mengarungi samudera cinta sejati. Fahri merupakan representasi dari laki-laki sempurna tanpa cela sedikitpun. Fahri adalah sosok laki-laki yang cerdas, berkemauan keras, visioner, saleh, dan teguh pada ajaran Islam.

Namun dibalik kesempurnaannya, ternyata Fahri menemukan cinta sejati tanpa melalui proses berpacaran seperti pada umumnya. Bahkan ketika memutuskan untuk menikah, Fahri sama sekali belum mengetahui bagaimana rupa calon istrinya, apalagi mengenal lebih jauh. Kebahagiaan cinta Fahri tidak diperoleh dalam masa pacaran karena Ia sadar betul bahwa cinta 
sejati dua insan berbeda jenis adalah cinta yang terjalin setelah akad nikah. Yaitu cinta pada pasangan hidup yang sah. Cinta sebelum menikah adalah cinta semu yang tidak perlu disakralkan dan diagungagungkan.

Pacaran hanya boleh dilakukan apabila antara laki-laki dan perempuan sudah bertekad akan melanjutkan hubungan ke jenjang pernikahan. Itu pun dengan aturan dan batasan-batasan yang telah ditentukan pula. Tujuannya adalah untuk saling mengenali dan mengerti tabiat dan sifat antara kedua belah pihak. Menurut Habiburrahman El Shirazy, ada beberapa hal yang harus diperhatikan dalam proses perkenalan antara laki-laki dan perempuan sebelum memutuskan untuk menikah, yaitu: (1) Utamakan laki-laki/perempuan yang memiliki pemahaman agama yang baik; (2) Sejauh mana konsistensi dan semangatnya dalam menjalankan syariat Islam; (3) Bagaimana akhlak dan kepribadiannya; (4) Bagaimana lingkungan keluarga dan temantemannya. Hubungan laki-laki dan perempuan dalam ajaran Islam disucikan sesuci-sucinya tanpa mengurangi keindahan romantismenya. Perasaan gembira, gugup, senang, bahagia, takut, dan campur aduk lainnya menghiasi laki-laki dan perempuan dalam proses ta'aruf.

Melalui novel karyanya, Habiburrahman El Shirazy ingin menunjukkan realitas yang terjadi pada kalangan remaja saat ini. Pergaulan bebas menjadi ancaman serius bagi moral remaja di kota, maupun di desa. Budaya yang datang dari luar Islam, kini menjadi trend mode modern yang mengancam generasi muda. Sudah menjadi rahasia umum bahwa free sex sudah menjadi bagian dari life style dan motif dasarnya sudah tidak lagi sebatas himpitan ekonomi. Inilah kelebihan Habiburrahman El Shirazy yang dimaksudkan dengan berdakwah tanpa menggurui namun esensi dan tujuan mulianya tetap mengena. Bagaimana rasa yang dialami Fahri dalam menemukan cinta sejatinya, muncul dalam diri remaja saat ini sebagai keindahan cinta.

\subsubsection{Ideologi yang muncul berdasarkan Biografi Habiburrahman El Shirazy}

Kisah di balik cerita novel Ayat-Ayat Cinta 2 yang Islami tidak luput dari latar belakang kehidupan Habiburrahman El Shirazy yang memang sejak kecil telah tinggal dilingkungan pesantren yang penuh dengan ajaran Islam. Oleh sebab itu novel Ayat-Ayat Cinta 2 terkesan merupakan sebuah pengalaman, kesan, harapan atau citacita dari pengarang tentang bagaimana seharusnya akhlak terpuji baik kepada Allah SWT, sesama manusia, maupun terhadap diri sendiri.

Dalam novel Ayat-Ayat Cinta 2, Habiburrahman El Shirazy mencoba mendeskripsikan pesan moral tentang nilainilai akhlak melalui cerita fiksi. yang dapat diketahui melalui tingkah laku, sikap, dan dialog yang dilakukan antartokoh. Berikut ini merupakan nilai-nilai akhlak dalam novel melalui kutipan-kutipan berikut ini:

"Maaf, bagi saya ini sudah tiba waktunya untuk ibadah. Apakah kalian terganggu jika saya shalat disini?. Jika kalian terganggu, saya akan shalat di office, lalu balik kesini. Atau kalian merasa cukup maka akan saya sudahi kelas ini" (Ayat-Ayat Cinta 2)

Dalam kutipan di atas terlihat jelas bahwa tokoh utama mempunyai sisi religius dan ketaatan yang sangat tinggi. Dilihat dari rutinitas tokoh utama dalam melakukan salat fardu yang selalu berusaha untuk mengerjakan salat fardu tepat waktunya. Bahkan di sela-sela mengajar ia rela mengakhiri kelas sementara waktu untuk mengerjakan salat fardu.

"Sudah masuk waktu Ashar. Sebelum pulang, kita shalat berjamaah dulu disini."Fahri mengambil dua sajadah yang ia letakkan dalam laci paling bawah meja kerjanya. Mereka berdua lalu tenggelam dalam 
kekhusyukan munajat kepada Allah saat hujan mengguyur Edinburgh, dan lonceng dari St. Giles Cathedral berdentang-dentang" (AyatAyat Cinta 2)

Dari kutipan di atas dapat diketahui bahwa tokoh-tokoh utama pada novel AyatAyat Cinta 2 merupakan orang yang sangat disiplin dalam beribadah, ia tidak mau melewatkan mengerjakan salat tepat waktu meskipun itu berjamaah atau pun sendiri, meskipun masih ada urusan sekalipun ia akan menundanya terlebih dahulu untuk mengerjakan salat.

"Ia berusaha mematikan alarm itu namun tidak juga mati. Tubuhnya yang terdiri dari materi yang sama dengan materi tanah menahannya untuk menggapai kemuliaan langit. Namun ruh Al-Qur'an yang mengeram didalam dada dan jiwanya membangkitkan kesadarannya." (Ayat-Ayat Cinta 2)

Berdasarkan kutipan di atas terlihat jelas pergulatan antara jiwa dan raga demi bangun untuk mengerjakan salat malam, namun akhirnya terbangun dan menjalankan salat malam. berusaha untuk selalu mengerjakan salat malam.

"Fahri lalu bergegas kekamar mandi untuk mengambil air wudhu. Waktu sepuluh menit ia gunakan untuk membaca AlQurean." (Ayat-Ayat Cinta 2)

Dari kutipan di atas dapat diketahui bahwa begitu disiplinnya tokoh utama dalam hal ibadah kepada Allah SWT. Ia bahkan tidak melewatkan rutinitas muraja" $a h$ hafalan Alquran agar hafalannya selalu terjaga. Tokoh-tokoh utama setiap hari melakukan muraja'ah di sela-sela waktu senggangnya.

"Fahri kaget mendengar jawaban Keira yang ketus itu. Paman Hulusi pun sedikit kaget. Maaf kalau pertanyaan itu membuat anda tidak berkenan" (Ayat-Ayat Cinta 2)

Dalam kutipan di atas terlihat jelas bahwa tokoh utama mencoba untuk ramah dengan Keira, Fahri mencoba untuk menyapanya namun Keira menjawab dengan sangat ketus. Melihat hal tersebut Fahri hanya bisa beristighfar dan menyabarkan dirinya menghadapi sikap Keira tersebut. Sikap sabar tersebut menggambarkan sosok yang istigfar,

"Imam itu istighfar, namun memandangi Fahri dengan sedikit kurang suka. Imam itu lalu membalikkan tubuhnya dan berdzikir. Ia sama sekali tidak berterima kasih kepada Fahri yang telah meluruskan bacaannya. Fahri sangat memaklumi dirinya agak diremehkan. Sebab ia berwajah Asia Tenggara dan tidak berjenggot." (Ayat-Ayat Cinta 2)

Dalam kutipan di atas terlihat jelas sikap sabar yang ditunjukkan oleh tokohtokoh utama pada novel-novel karya HES menyabarkan dirinya saat dia diremehkan oleh Imam muda yang bacaannya diluruskannya, karena dia sudah bisa memakluminya seperti dulu saat berada di Jerman.

"Di kertas HVS itu ada tulisan pakai spidol merah tebal yang bunyinya: MUSLIM=MONSTER!.

Fahri dan Misbah membaca istighfar." (Ayat-Ayat Cinta 2)

Dari kutipan di atas terlihat jelas bahwa Fahri hanya beristighfar menghadapi ulah orang yang membuat coretan itu dan tidak begitu menanggapi coretan itu, namun ia malah menjadikan tulisan itu cambuk bagi dirinya. Sebab ia tidak ingin terjadi keributan dengan tetangganya hanya karena hal sepele seperti itu.

"Aku paling mengerti Aisha. Aku paling mencintai Aisha 
setelah ibunya. Aku, Paman! Dan aku tidak bermesraan dengan nenek-nenek Yahudi. Jangan melihat Yahudinya, Jangan“" (Ayat-Ayat Cinta 2)

Berdasarkan kutipan di atas terlihat jelas Fahri sangat sabar menghadapi Paman Hulusi yang tidak menyukai orang Yahudi, namun sebagai seorang yang penuh belas kasihan Fahri tidak pernah membedabedakan orang dalam memberi bantuan kepada siapapun.

"Sudah biarkan saja Paman. Ayo masuk dan shalat Maghrib. Ini sudah Maghrib. Kita doakan saja tetangga kita terbuka hatinya dan bisa bersikap lebih baik." (AyatAyat Cinta 2)

Berdasarkan kutipan di atas terlihat jelas bahwa tokoh-tokoh utama pada novel begitu sabar meskipun sikap yang mencoba untuk ramah pada tetangganya selalu dibalas dengan ketus dan bahkan ia menasihati Paman Hulusi agar lebih bersabar lagi.

Berdasarkan kutipan-kutipan di atas, diketahui bahwa menurut Habiburrahman El Shirazy, ajaran Islam tidak hanya mengatur hubungan manusia dengan Allah, tetapi juga mengatur hubungan dengan sesama manusia, seperti ajaran untuk memuliakan sesama manusia, menghormati orang yang lebih tua, menghormati istri, menghormati tamu, dan menjaga pergaulan dengan lawan jenis. Dalam novel karyanya Habiburrahman El Shirazy mengajak semua umat Islam dapat memuliakan sesama manusia, baik muslim maupun non muslim.

Menurut Habiburrahman El Shirazy, seorang muslim harus menghormati sesama manusia. Seorang muslim juga diperintahkan untuk berkata yang baik terhadap sesama manusia dan menghindari kata-kata yang kotor dan hal tersebut sesuai dengan surat AlBaqarah 83 disebutkan, "Hendaklah kamu berkata terhadap manusia dengan perkataan yang baik-baik". Ajaran itu dapat dilihat ketika salah satu tokoh utama dalam memberikan tempat duduknya didalam bus kepada seorang penumpang turis dari Amerika. Orang-orang di dalam bus memprotes tindakan tokoh utama tersebut karena orang Amerika dianggap sebagai musuh orang muslim. Kemudian Habiburrahman El Shirazy melalui tokoh utama tersebut mengingatkan saudarasaudaranya sesama muslim bahwa agama Islam melarang pemeluknya untuk mengumpat dan mengeluarkan kata-kata kotor

Kemudian, Habiburrahman El Shirazy juga mengajarkan bahwa sebagai seorang muslim, harus mengajarkan umatnya untuk mencintai dan menghormati sesama manusia meskipun berbeda agama, suku, dan golongannya, Orang asing yang masuk ke negara muslim secara resmi dan baik-baik disebut ahlu dzimmah dan mereka berhak untuk dihormati. Habiburrahman El Shirazy melalui tokoh utama mencegah saudara sesama muslim untuk menzalimi orang-orang yang non muslim dengan menunjukkan sebuah hadis seperti berikut. "Tidakkah kalian dengar sabda beliau,'Barangsiapa menyakiti orang zhimmi (ahlu dzimmah) maka aku akan menjadi seterunya. Dan siapa yang aku menjadi seterunya dia pasti kalah di hari kiamat.

\section{Saran}

Berdasarkan paparan di atas diketahui bahwa ideologi yang melatarbelakangi novel Ayat-Ayat Cinta 2 adalah ideologi Islam yang kaya akan ilmu pengetahuan dan ajaran Islam yang mengajarkan kebaikan. Dan ajaran tersebut juga merupakan ajaran Islam yang toleran terhadap agama lain. Apabila di kaitkan dengan fenomena yang terjadi di Indonesia belakangan ini yaitu pertikaian antaragama, maka novel ini sangat tepat dijadikan sebagai rujukan untuk dibaca oleh orang-orang yang memiliki pandangan yang salah tentang Islam agar mendapatkan pencerahan tentang Islam yang Rahmatan Lil'Alamin. Oleh sebab itu melalui hasil penelitian ini, diharapkan agar:

1. Pemerintah dapat mengapresiasi setiap novel-novel yang berisi tentang 
kebaikan melalui kisahnya yang membawa perdamaian dan cita-cita Pancasila serta Bineka Tunggal Ika

2. Para tokoh agama dari agama apa pun

\section{DAFTAR PUSTAKA}

El Shirazy, Habiburrahman. (2015). AyatAyat Cinta 2. Jakarta: Republika

Eriyanto. (2006). Pengantar Analisis Wacana. Pengantar Analisis Teks Media. Yogyakarta: Lkis

Foucault. (1971). L'ordre du discours. Gallimard. Paris

Leeuwen T. Van. (2001). Multimodal discourse: the modes and media of contemporary communication. London. Arnold

Miles, Metthew B, A. Michael Huberman and Johnny Saldana. (2014). Qualitative Data Analysis, A di Indonesia, hendaknya menjadikan novel ini salah satu sebagai tolak ukur atau platform untuk menciptakan perdamaian antarumat beragama.

\section{Methods Sourcebook, Third} Edition. Sage Publications, Inc.

Mills, Sara. (1994). Critical Discourse Analysis of Female. Oxford: Blackwell Publishers.

Roekminto. (2008). Metode Penelitian Sastra: Analisis Psikologi. Surakarta: Sebelas Maret University Press.

Sugihastuti, Suharto. (2002). Kritik Sastra Feminis, Teori dan Aplikasinya. Yogyakarta: Pustaka Pelajar

Van Dijk, Teun A. Ed. (1993). Handbook of Discourse Analisis: Discourse Analisys in society. London. Academic Press, Inc. 